\title{
General Condition of Iron and Steel Industry of U.S.S.R."
}

\author{
By Tatsuo Hayashi**
}

\section{Outline and Impression of Visit of U.S.S.R.}

In August 1963 the Iron and Steel Delegation of U.S.S.R. came to Japan. The leader was Mr. Boiko, Minister, and Dr. Samarin joined in the party as the assistant leader. Considering that one such party after another will visit U.S.S.R. in the future, The Japan Iron and Steel Federation decided to send the Japan Delegation of Special Steels to U.S.S.R. as a leading party with the intention of returning the courtesy. The purpose of our delegation was the promotion of technical interchange; we also intended to further develop future economical exchange. We also had an intention to rationalize mutual trade through our careful observation of conditions in U.S.S.R. as we had been inclined to so-called blind trade against the communist bloc.

We, the members of the delegation were eleven in all, consisting of eight representatives of eight special steel manufacturing companies, one representative from The Japan Iron and Steel Federation as a secretary and two members as interpreters. From October 1 to October 22, 1964, we travelled considerably. We could deepen mutual understanding through our frank conversations about iron and steel, which we believe were very significant. As the visit was the first one for us, we had prepared a tremendously busy schedule. Fortunately, thanks to the kindness and the assistance rendered by the corresponding organizations of U.S.S.R. or the people with whom we had connection, we were able to travel smoothly and visit six metallurgical mills, five machinery plants, four laboratories and four Governmental organizations.

We visited mainly those plants in the region of the Ukraine, but aside from them we also visited eight principal cities such as Moscow, Leningrad, etc. and talked with a good many people. I am collecting foreigners ' signatures as a hobby, and I collected over one hundred. In addition to such travel for purposes of observation, three gentlemen of our delegation introduced the topic of special steels in Japan at the lecture meetings. Also we held round-table conferences about trading and talked with representatives of Japanese trading companies there. Furthermore, we had a chance to call on the Embassy where we could learn of various situations in U.S.S.R. Although our schedule was very tight, we set aside ample time for sightseeing and could have some opportunities to visit art museums. We also tried our best to study the nature and customs of the Russian people as much as we

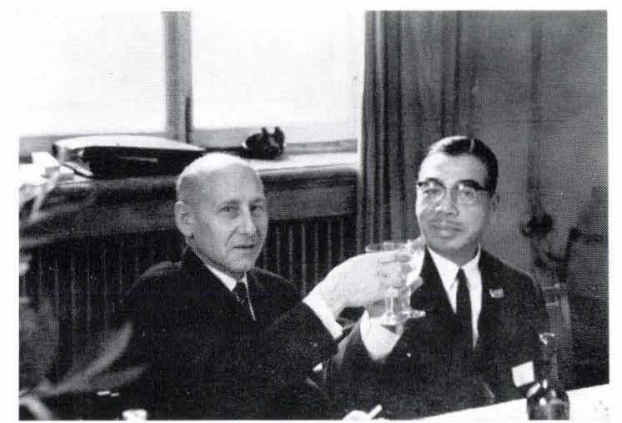

Chief of the Central Iron and Steel Laboratory (on the left) and the author

could. As Mr. Boiko, the Minister who came to Japan as the leader of the Iron and Steel Delegation of U.S.S.R. had reported there that Japanese manufacturing facilities and techniques of iron and steel production were excellent, we were greatly welcomed everywhere.

Whenever we visited their plants we found unexpectedly the plant managers standing "at attention" to greet us. Among them there were always some women and we noticed that their educational opportunities were equal to those of the men. And as a matter of fact women held positions everywhere. The head manager is called "director".

First of all, they explained the organization and work of the plant and as far as the time permitted showed us every corner which we wanted to see; they also answered all of our questions very kindly. When we asked them, in one of large plants we visited, how large the plant was, they could not give us the right answer. Therefore, we wondered if they were hiding the answer from us, but now we recall that the land belongs to the Government and they had no interest in the size of the land and the land fee. We Japanese are very keen about the estimated value of land and the relative investment, but they have the least interest in them and they show a look of wonder when asked about the land fee. They have an easy-going attitude if in extending their plant, they have to sacrifice the wheat fields near-by. The surroundings of their plants are so scenic that one gets the impression that the plants are standing in the parks. On the other hand, the inside of the plants seems to be confining and dark with few windows, but this impression may well be due to climate. Such limitation and darkness are mostly seen at metallurgical mills, and since we are accustomed to see those Japanese plants well arranged these days, we think that we might have such impression not only

* This report is in reference to the Special Lecture Meeting held by The Japan Iron and Steel Federation and The Iron and Steel Institute of Japan in March 26, 1965 in Tokyo.

** Leader of the Delegation, Dr. Eng., Vice-President, Daido Steel Co., Ltd. 
in U.S.S.R. but in other countries. As for their machinery plants they are paying more attention in this regard and at some we found potted plants and tropical flowers arranged.

In U.S.S.R. there are a good many women labourers. At those metallurgical and machinery plants we observed that 20 to 50 per cent of the labourers were women. We further heard that nearly 100 per cent of the workers in light industries were women. Women labourers are engaging even in steelmaking plants which require very hard work and they also work on night shift; there is no work discrimination between men and women. Needless to say, they are all equally paid, there is the same wage for the same kinds of labour. Therefore, they wondered very much why Japanese women were not working on night shift. Also they told us that they had no statistics of average wages according to sexual difference. Since everyone, regardless of sex, is able to enjoy same educational opportunity, there are women directors in plants.

The hope or ambitions of young boys and girls has been changing. In old days men used to enter the Communist Party - at present only four per cent of the nation are members - and wish to become leaders. Instead, most young people want to be scientists or engineers. It seems that this tendency is common in all communist countries. In order to industrialize the country the Government treats scientific engineers very highly in U.S.S.R. and their social status is extremely high, which, we think, makes young Soviet people ambitious. All women, however, are not exactly able to get such high positions. Many of them, we heard, want to be artists, ballet dancers like Kondrativa, or musicians.

\section{Economy of U.S.S.R. and Characteristics of Enterprise}

Talking of U.S.S.R. we always recall the term of "Norma", and as a matter of fact "Norma" is considered very severe. In U.S.S.R. not only each enterprise but also each individual and group are being burdened with "Norma ", a fact which has close connection with the nation's economic development. Conventionally more emphasis has been put on " quantity ", but recently " Norma " has been emphasized in not only "quantity", but improvement of quality, reduction of cost, curtailment of labours, elevation of efficiency, etc. It can be said that the change indicates a lesser emphasis on quantity and greater stress on quantity and greater stress on quality.

Here we should refer to the principle of the Soviet economy. This country is a so-called socialistic state, its economy is directly related to the Government and it is co-ordinated like a single unified plant. The characteristic enterprise is Government owned. Government owned enterprises are supplied the necessary land, materials and funds by the state. There are also union enterprises which borrow materials and funds from the state and are required to return them. All the transactions between these enterprises are financially settled by booking account and no transferring of currency is seen. Each enterprise is managed on an independent profit basis. In case an enterprise exceeds "Norma", it is repaid as a form of bonus and it uses these returns for rationalization for the welfare of the labour union. It is also partially used for wage increase of labourers. Being different from the free economy each enterprise does not need any business expenses and does not need to cover interests or make depreciations, since land, building, materials are

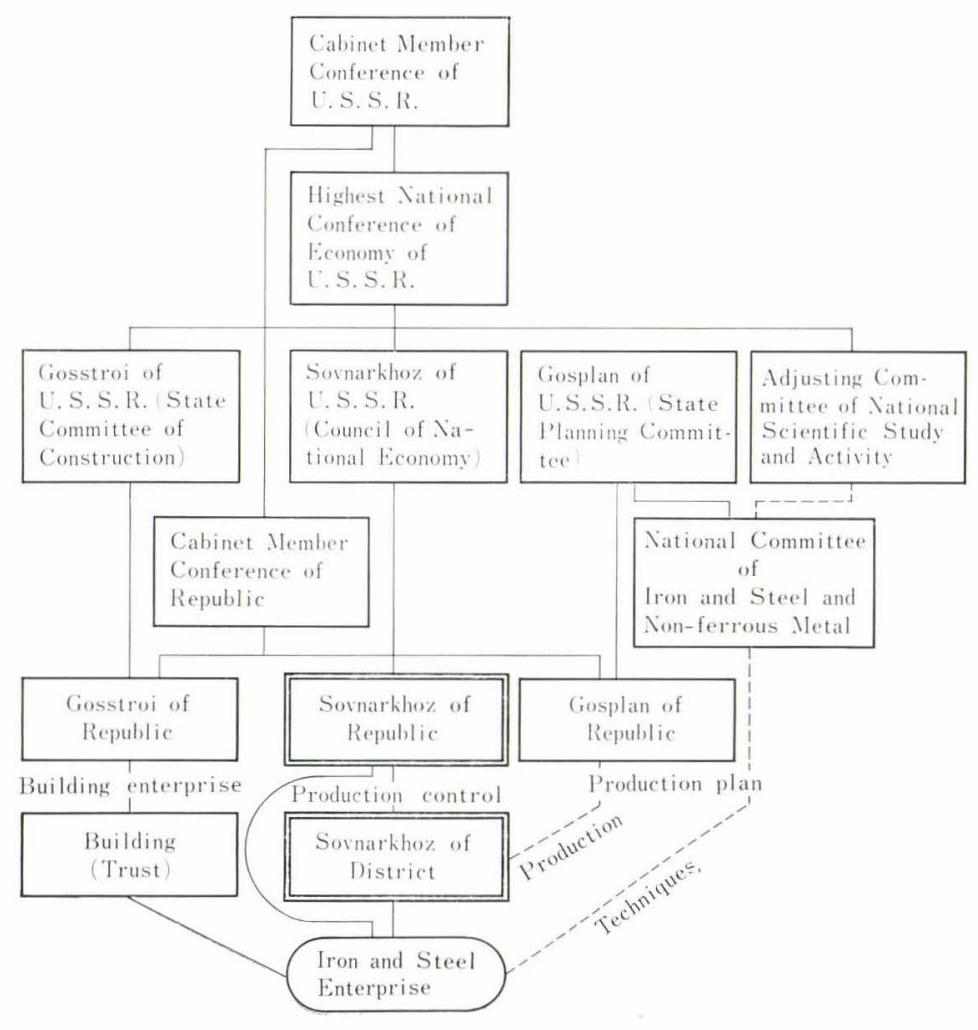

Administrative organization of iron and steel enterprise 


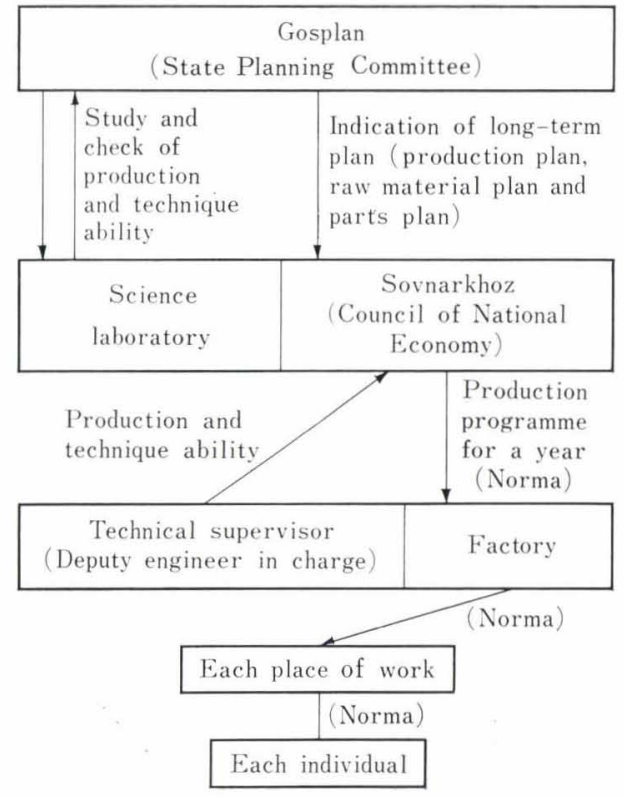

Production organization

being supplied or lent to them by the state. And balances are settled by booking account. In addition there is a tendency to concentrate steel production classified by grades. With diligent man-power the cost of producing materials is naturally low and the price of special steels is considered to be generally lower compared with that of nations operating under a free economy. All the prices of commodities are fixed by governmental organization. That is to say, the prices are called official prices. The prices of general consumer goods are fixed on the basis of their original cost. In such case as the price influences directly the life of nation or in such goods that have much influence on reproduction, the Government sometimes fixes the prices below the original cost. On the contrary the prices of those goods other than necessities are fixed higher. From this pricing we supposed that the socialistic price policy is naturally being applied.

\section{Iron and Steel Plan in U.S.S.R.}

As it is well known U.S.S.R. is the second largest iron and steel producing country. The production of crude steel was 54.9 million tons in 1958 and from 1959 to 1962 she increased her total amount by 5.4 million tons each year. At the end of 1963 the Soviets made a production plan for 1964-65 and decided upon 89.3 million tons as the target of crude steel production. The actual result in 1964 was 84.7 million tons and that of $1965,90.7$ million tons. According to the statistics of 1964 the United States of America produced 118 million tons and U.S.S.R. 84.7 million tons. According to Minister Boiko's announcement on the role of iron and steel industry in the long term plan of U.S.S.R. for economic development in 1966-70, they have been extending, for the past several years, the production of new and progressive divisions and raising efficiency of enterprise activities to full extent by making the best use of the latest scientific techniques. As emphasized in U.S.S.R. the Highest People Conference of Economy held in December 1964, they are improving quality of goods, are increasing the variety, are producing economically and also are trying their best to increase production of all kinds of steel plates and steel pipes. Furthermore, in line with the progress of development in the chemical industry, electrical industry, electronics industry and other divisions, they are seriously considering the development of new

Production index of mine industry

\begin{tabular}{l|l|l|l}
\hline & U.S.S.R. & U.S.A. & Japan \\
\hline 1938 & 18 & 33 & 57 \\
\hline 1948 & 27 & 73 & 22 \\
\hline 1953 & 59 & 97 & 60 \\
\hline 1955 & 74 & 103 & 69 \\
\hline 1956 & $82(111)$ & $107(104)$ & $86(125)$ \\
\hline 1957 & $91(111)$ & $107(100)$ & $99(115)$ \\
\hline 1958 & $100(109)$ & $100(93)$ & $100(101)$ \\
\hline 1959 & $111(111)$ & $113(113)$ & $124(124)$ \\
\hline 1960 & $122(110)$ & $116(103)$ & $156(126)$ \\
\hline 1961 & $133(109)$ & $117(101)$ & $186(119)$ \\
\hline 1962 & $146(110)$ & $126(108)$ & $201(108)$ \\
\hline Notes: & 1958 is supposed to be 100. & \\
\hline & figures in round brackets are ratio of preceding year. \\
\hline
\end{tabular}

Target of seven-year iron and steel plan (1959-'65) and production tendency

\begin{tabular}{|c|c|c|c|c|c|}
\hline & & $\begin{array}{l}\text { Crude steel output } \\
\qquad\left(\times 10^{6} \mathrm{t}\right)\end{array}$ & $\underset{(\%)}{\text { Increasing rate } / y r}$ & Steel material output & $\underset{(\%)}{\text { Increasing }}$ rate/yr \\
\hline Actual & 1958 & 54.9 & - & 43.1 & - \\
\hline \multirow{6}{*}{ Results } & 1959 & 60.0 & 9 & 47.0 & 9 \\
\hline & 1960 & 65.3 & 9 & 51.0 & 8 \\
\hline & 1961 & 70.8 & 8 & 55.3 & 8 \\
\hline & 1962 & 76.3 & 8 & 59.2 & 7 \\
\hline & 1963 & 80.2 & 5 & 62.4 & 4.7 \\
\hline & 1964 & 84.7 & 5.6 & - & - \\
\hline \multicolumn{2}{|c|}{ Initial plan target of 1965} & $86-91$ & 7 (yearly average) & $65-70$ & 4.6 (yearly average) \\
\hline \multicolumn{2}{|c|}{1963 amended plan target of 1965} & 89.3 & & 69.0 & \\
\hline
\end{tabular}


Developing plan of whole production of industry, crude steel and machinery industry in U.S.S.R. decided in 1961

\begin{tabular}{l|c|c|c} 
& \multicolumn{3}{|c}{ Developing index } \\
\cline { 2 - 4 } & 1960 & 1970 & 1980 \\
\hline Whole production of industry & 100 & 263 & 630 \\
\hline Production of crude steel & 100 & 224 & 384 \\
\hline Production of machinery industry & 100 & 338 & 1030 \\
\hline
\end{tabular}

ferro-alloy and new corrosion and heat resisting steel with special physical properties and high purity and hardness.

\section{Summary of Iron and Steel Techniques in U.S.S.R.}

We observed as many as 15 plants and laboratories. Stating about metallurgy, those divisions that require less additional work have been considerably advanced. Blast furnaces have, from the world-level point of view, been developed most and high pressure operation seems to be extremely advanced. It was said that they are making use of natural gas, they even have blast furnaces of $2700 \mathrm{~m}^{3}$ capacity. They also have open hearth furnaces as large as 500 to 600 tons of capacity and are using natural gas for the operation of those furnaces, too. They are producing a great deal of hearth furnace steel and the relative techniques are also supposed to be advanced. According to the statistics of U.S.S.R. in 1962 the output of crude steel was 64924000 tons $(85 \%)$ by open hearth furnaces, 6818000 tons $(9 \%)$ by electric furnaces, 4564000 tons $(6 \%)$ by converters (Bessemer and LD) and 85 per cent of total output of crude steel was produced by open hearth furnaces.

\section{Steelmaking}

Policy of Steelmaking in U.S.S.R.

Mr. Boiko, Chairman of National Committee of Iron and Steel and Non-Ferrous Metals announced an article titled " U.S.S.R.'s Opinion about Iron and Steel Techniques" in Pravda dated June 8, 1962. And in the article it was stated that they would not erect open hearth furnaces as a rule but should build oxygen converters and electric furnaces as future steelmaking facilities. Therefore, only those open hearth

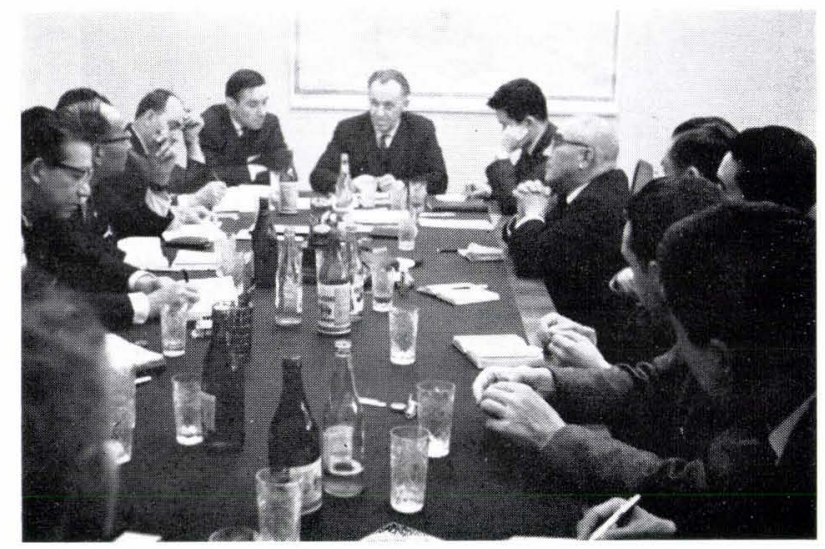

A talk at GKKNIR. Dr. Samarin (in the centre) furnaces which had already been ordered would be constructed and all the rest would be changed to the LD converters. They are using present facilities to full extent. They are studying the open hearth furnace steelmaking process at open hearth furnace plants and the electric furnace steelmaking process at electric furnace plants thoroughly. They are also aiming toward high efficient operation by specializing the production of one grade of steel at one plant and evading production of various grades of steel at another. Though the building of larger size electric furnaces is a world-wide tendency, the capacity would be 100 to 150 tons, not so large as 250 tons. As a standard it is said that they have built a 300 -ton electric furnace.

\section{Steelmaking Techniques}

In case oxygen blowing facilities are installed at a furnace, oxygen is blown into slag through the lance protected by cooling pipes from ceiling both for open hearth furnaces and electric furnaces. For an open hearth furnace two lances were found hanging over the central part of both side doors and for an electric furnace it was installed in front of No. 2 electrode or a bit closer to the furnace wall on the line connecting Nos. 1 and 3 electrodes. Degassing units are installed at Dneprospetzstal plant: there droplet degassing of the ladle method is operated with reduced pressure of three to four $\mathrm{mmHg}$ and a mechanical booster. Degassed steel is called vacuum steel and is being distinguished from atmosphere casted steels, but it seems that the quantity of this vacuum steel is small. It is said that slag composition analysis by spectroanalysis using arc between slag and electrode is being adopted at mills, and they are also developing to enable continuous analysis of steel bath.

\section{Raw Materials for Special Steels}

High quality materials other than scraps and pig irons, for instance, sponge irons, are not particularly considered for use as tool steels or higher grade steels for the following reasons:

(1) They are not suitable for mass production.

(2) There is no problem if they are cheap. But there is no need of raising efficiency by improving quality of materials as artificial diamonds can be used as tooling materials.

(3) Quality can be improved at the stage of steelmaking.

\section{Electro Slag Remelting Method}

At the end of 1954, it is said that this method was developed at Kiev Paton Memorial Electric Welding Laboratory and was put into practical use at the plant in 1958. This is an effective refining method for improving the quality of steels; and it is being studied in U.S.A. as the Hopkins method, while in England BISRA is studying the same. It seems that the techniques have been considerably advanced in U.S.S.R. At the Dneprospetzstal plant a new plant for this electro slag remelting method had been completed and there are found one unit of large size, three units of medium size, three units of small size, with single or three phase electrodes. 140 to $150 \mathrm{~mm}$ square billets as electrodes rolled by blooming mill are being 
used. Most of the products made in this plant are 300 to $400 \mathrm{~kg}$ and ingots $270 \mathrm{~mm}$ round with clean surface and are mainly bearing steels. One example of operating conditions: in case of producing 720$750 \mathrm{~kg}$ and $300 \mathrm{~mm}$ diameter ingot. Consumable current: 6000-6 $600 \mathrm{~A}$, electric pressure: 60-55 V, consumption of flux : $21-23 \mathrm{~kg}$. The melting method is similar to that of conventional vacuum arc melting and the characteristics of products are also like those of vacuum arc melted materials: decrease of impure gas, decrease of metallic inclusions and improvement of material properties. It requires no vacuum exhausting system and brings better results when alternating current rather than direct current is used. And for these reasons it seems that this special method is better developed in U.S.S.R. than are vacuum arc melting techniques.

\section{Ingot Making Method}

The difference between their method and the Japanese method is, to our surprise, that they apply bottom pouring even in manufacturing special steels. We think that top pouring is better for manufacturing high class special steels, but throughout they apply bottom pouring. There are various problems in it, but we think that they are doing it for economic and practical purposes.

\section{Continuous Casting}

Iron and steel industries all over the world are now paying attention to the economic and technical movement of the continuous casting process. At present, 10 metallurgical mills and 14 facilities are in operation on an industrial scale. Fortunately, we could observe the typical plants of Novo-Lipetsk and Donetsk and also the Central Iron and Steel Laboratory.

\section{Steel Grade and Quality}

Their technical level of continuous casting process including the refining process of molten metal is high and the surface condition of cast slab is quite smoothly beautiful with almost no defects but just a few chippings.

Type

As the casting machines are as high as the deck of steelmaking furnaces, most of them are of the undergroud type with a considerable working space. On the other hand, however, the vertical type requires underground construction work at about $25 \mathrm{~m}$ below ground level. Therefore, the curved type steel output by continuous casting in U.S.S.R. a process now under study, is about 1.5 million tons per year, which is nearly more than half of what is produced by the continous casting process in the whole world. They are proud of the advancement in industrial development, since their steel industries are on an extremely big scale and modernized.

At Novo-Lipetsk metallurgical plant they have two units of 100-ton electric furnace and hot metal electric furnaces are constantly treated mostly by continuous machine. The continuous casting machine at Donetsk plant is casting about 140 ton hot metal by one ladle. Both single and multi-strands are used in continuous casting machines. And the fundamental type of
U.S.S.R. continuous casting machine is, as far as industrial machines are concerned, vertical. Moulds are made of copper and for lubricants they are using a special kind (they call it "solid paraffin ") in order to prevent oxidization of cast hot metal surface propane is used. Cast ingots are cut by oxygen acetylene and cut pieces are lifted up to the ground by a conveyor or a lift. At the two plants, which we observed, ordinary carbon steel (killed, rimmed) low alloy steel, silicon steel, etc. were being produced but tool steels, bearing steels, steels containing tungsten, molybdenum and stainless steels were not. Most of the products were slabs of $100-200 \mathrm{~mm} \times 600-1500 \mathrm{~mm}$ and they were also producing square materials of $125-300 \mathrm{~mm} \mathrm{sec-}$ tion.

The Central Iron and Steel Laboratory is pursuing the basic study of c.c., from the aspects of metallurgical, physical or thermal property of steel as the leader and shows the plan of facilities. According to this plan, the National Metallurgical Plant Designing Laboratory engages in designing, instrument controlling units necessary for the design is treated by the Instrument Controlling System Designing Laboratory, and the National Fundamental Construction Work Designing Laboratory constructs experimental plants of mass production scale. The Central Iron and Steel Laboratory checks systematically all of those different data obtained from operation at such experimental plants and also they utilize the data for regular plant construction. By repeating research work, developing and enterprising they have established at the present time the foundation for continuous casting techniques.

List of outline of continuous casting equipment

\begin{tabular}{|c|c|c|c|}
\hline & Plant & Novo-Lipetsk Met. P. & Donetsk Met. P. \\
\hline & peration year & 1959 & 1960 \\
\hline & itput & $\begin{array}{l}\text { Approx. } 300000 \\
\text { ton/year }\end{array}$ & $\begin{array}{l}\text { Approx. } 200000- \\
250000 \text { ton/year }\end{array}$ \\
\hline & eelmaking f'ce & $\begin{array}{l}2 \text { units of } 100 \text {-ton } \\
\text { electric f'ce }\end{array}$ & $\begin{array}{l}8 \text { units of } 145 \text {-ton } \\
\text { open hearth f'ce }\end{array}$ \\
\hline & eel grade & $\begin{array}{l}\text { Ordinary carbon } \\
\text { steel (killed) (rimmed) } \\
\text { Silicon steel ( } 3 \% \mathrm{Si})\end{array}$ & $\begin{array}{l}\text { Ordinary carbon } \\
\text { steel (killed) (rimmed) } \\
\text { Low alloy steel }\end{array}$ \\
\hline & $\begin{array}{l}\text { easurement of } \\
\text { ast piece }\end{array}$ & $\begin{array}{c}100-120 \times 620-1040 \\
\times \text { approx. } 4000\end{array}$ & $\begin{array}{l}120-200 \times 600-1200 \\
\times 4200-5200\end{array}$ \\
\hline & umber of strand & 2 & 4 \\
\hline & Capacity (t) & 8 & 8 \\
\hline $\bar{g}$ & Nozzel (mm) & $28($ round $) \times 2$ & $28($ round $) \times 2$ \\
\hline 5 & Number & 1 & 2 \\
\hline & $\begin{array}{l}\text { Measurement } \\
(\mathrm{mm})\end{array}$ & 1500 (height) $\times 20$ (thick) & $1500($ height $) \times 20($ thick $)$ \\
\hline$\frac{\pi}{7}$ & Stroke (mm) & 28 & 20 \\
\hline$\Sigma$ & $\begin{array}{l}\text { Vibration } \\
\text { number }\end{array}$ & 30 times $/ \mathrm{min}$ & - \\
\hline & Lubricant & Special lubricant & Special lubricant \\
\hline & $\begin{array}{l}\text { evention of } \\
\text { oxidization }\end{array}$ & Propane & Propane \\
\hline & tting & Oxygen acetylene & Oxygen acetylene \\
\hline & $\begin{array}{l}\text { sting speed } \\
\mathrm{mm} / \mathrm{min})\end{array}$ & 800 & 800 \\
\hline
\end{tabular}




\section{Rolling and Conditioning}

This time we visited the underwritten five plants relating to rolling and they have various facilities of all ages.

Novo-Lipetsk Metallurgical Plant

Donetsk

Zaporozhye

,

Dneprospetzstal Plan

Leningrad Iron and Steel Rolling Mill

In U.S.S.R. they are strongly promoting the specialization of products according to the characteristics of each plant. Generally speaking, they have few new facilities and are making the best use of conventional facilities and planning to improve rolling speed, productivity by increasing and changing stand positions. On the other hand, they are also trying their best to develop facilities through their own techniques and are manufacturing big rolling machine of 20 stands. For instance, performances of blooming mill "1 300 " installed at Krivoi-Rog metallurgical plant and continuous type rolling mill " 30-102" at Pervural steel pipe plant are superior to similar mills made by foreign manufacturers. It is worth noticing their development of planetary wire rod rolling mills, planetary steel pipe rolling mills, etc., though they were not included in our visiting schedule this time. Besides these main facilities it is interesting to know that large size bar straightener, bar-turning are being developed as auxiliary facilities entirely by themselves and are in practical use. The quality of products seems, generally speaking, to be inferior, which could be for the reason that quantity is required more than quality at this stage. Especially surface conditions seemed to be scarcely acceptable for practical use. The hardness of work roll for rolling is considerably low and has some influence on surface conditions of products.

\section{Heat Treatment}

In U.S.S.R. most alloy steels are delivered to plants after heat treatment. The facilities at the heat treatment plant of Dneprospetzstal mill are normalizing furnaces and tempering furnaces. They are of the batch type furnace and have a capacity of 30 tons. As heat source they were using a mixture (1 $700 \mathrm{kcal}$ ) of natural gas, coke gas and blast furnace gas. For charging to and discharging from furnaces fork-lift with rail was being used. In order to raise efficiency of air cooling there are seven holes in three rows on the furnace hearth and at the tail of a furnace there is a big ejector for improving air cooling efficiency. At Kiev Gorkii Memorial Automobile Machine Tool Factory they were carburizing gears of machine tool. The inside was well-arranged and there were two units of round temper furnace, eight units of batch furnace and four units of round pit type gas carburizing furnace treated by the carburizing method using natural gas found abundantly in the area. Most steel grade of gears are of case-hardening steel of chrome only and the specifications are as follows:

Carburizing depth: approx. 1 (one) $\mathrm{mm}$

Surface hardness: HRC 60-64
Inside hardness : $\quad$ HRC 35-45

Kalinin Memorial Frezer Grinding Tool Plant is the first special plant for tools in U.S.S.R. and there they are producing all kinds of grinding tools like bit, drill, milling reamer, etc. Their heat-treatment furnaces are all salt baths and at each special tool plant various sizes of salt baths are being used. As to the steel grade $80 \%$ is $\mathrm{P} 18$ of $18-4-1$ series high speed steel and $20 \%$ are alloy tool steel $9 \times \mathrm{C}$ and carbon tool steel. At heat-treatment plants for small materials, there is an interesting way measuring of temperature - the method of small size infrared thermometer. At plants for large materials there were special heattreatment plants of approx. $1000 \mathrm{~m}^{2}$ and numerous salt baths of small and big sizes were well arranged as found at other mills and among them there were a large size drill and two rows of continuous style salt bath lines only for reamer. The type is of straight line and is interesting for us, because it was just contrary to the merry-go-round type applied in U.S.A. and European countries. The tempering line consisted of $850^{\circ} \mathrm{C}$ preheating bath $1280^{\circ} \mathrm{C}$ hardening and heating bath, $570^{\circ} \mathrm{C}$ drawing bath and $830^{\circ} \mathrm{C}$ high temp. tempering bath for the shank of drill, 30-40 pieces drills in a triangular steel basket were being heat treated one after another. At the heat-treatment plant there were two television cameras and they were ready to show the operating conditions on the screens placed at the Plant Manager's room and central control room at any time, which impressed us very much. The heat-treatment furnace of a complete automation line of bearings, which is said to have been completed in 1956, is an automatic furnace requiring no manual help. We observed there a conditioning operation of $80 \mathrm{~mm}$ out-diameter bearings in combination of inside and outside laces in a hardening furnace. The hardening furnace is a shaker furnace of approximately $100 \mathrm{~kW}$ of electric heating. After rapidly cooled in oil, materials are lifted by a conveyor and put into subzero apparatus of $-13^{\circ} \mathrm{C}$ after being washed by caustic soda to avoid age deformation, and then sent to the tempering furnace. This furnace had five fans up on the ceiling for making uniform inside temperature distribution. Neutral protecting gas is used in order to avoid scale and decarburization as atmospheric gas of hardening furnace. We can say that this automation line was the most excellent one among all of the heat treatment apparatuses we observed in U.S.S.R.

\section{Standards}

\section{National Standard}

In U.S.S.R. they have a national single standard called GOST which is applied in every field throughout the country. This standard is very compulsory. All special steel grades to be melted by the open hearth furnace are specified according to this GOST standard. The standard is mainly fixed according to the economic property of yield of alloy addition and the influence of its quality on usage. What we call special steels in Japan, however, are almost similar to those steels stimulated in Part 2 II A chemical compositions of 
superior quality and extraordinary superior quality of U.S.S.R. National Standard (GOST) and they are hot and cold worked rolled and forged round, square, flat, hexagonal, section, hoop, thick plate, thin plate, wire and pipe. The contents of steel grades are as follows:

i. Steel for Structural Use

Medium carbon steel, medium alloy steel, high grade alloy steel, bearing steel, free cutting steel, medium steel for spring, higher grade steel for spring. ii. Tool Steel

Medium carbon steel, higher grade carbon steel, higher grade alloy steel, high speed steel.

iii. Special Steel

Stainless steel, corrosion resistant steel, heat resistant steel, high electricity resistant alloy steel, steel with special physical properties, steel for welding rod, and other special steels.

\section{Application and Readjustment of National Standard of GOST}

The application is executed by the National Standard, Measurement and Measuring Implement Committee of the U.S.S.R. Cabinet and in accordance with the projects adopted every year. The draft is compiled by the National Iron, Steel and Non-ferrous Metal Committee after consulation with users, producers, representatives of special academic association scholars, etc. After the opinions of users and producers are taken into account, this initial draft is returned to the office in charge of compiling it. It is then sent to the regular committee through the National Iron, Steel and Non-ferrous Metal Committee as the final draft and the committee decides upon it after serious deliberation. Finally the decision is announced officially all over U.S.S.R. and will have binding force. Almost the same steps are taken for readjustment, too.

\section{Some Comments on Standard}

In our country each company is freely producing identical steel grade, but with slight differences in standard, while in U.S.S.R. everything is nationally controlled. Since circumstances are considerably different between the two countries, steel manufacture can not be simply compared, but we think that we should have a single standard and make it binding. In order to realize this we must undertake the fundamental step of inducing companies to conform to a single standard for identical products, since we feel keenly the need for such a measure.

\section{Researches}

As for researches we visited the Central Iron and Steel Laboratory, Baikov Memorial Iron and Steel
Laboratory, Kiev Paton Memorial Electric Welding Laboratory and Secondary Metal Product Plant Designing Laboratory. The Central Iron and Steel Laboratory and Baikov Memorial Iron and Steel Laboratory are directed by the National Iron, Steel and Non-ferrous Metal Committee. The Baikov Memorial Iron and Steel Laboratory had been directed by the U.S.S.R. Science Academy until 1961, but then came under the directorship of the National Iron, Steel and Non-ferrous Metal Committee, the very quarter of the iron and steel industry whose work it is to increase the production and promotion of iron and steel techniques, which the country is emphasizing most strongly. The characters of these two committees are quite contrary to each other, that is to say, the former is mainly for practical and applied study; the latter, for theoretical and basic study. The achievements of both laboratories have been highly evaluated internationally. Both laboratories have strong authority; they give directions to a laboratory of each area "Sovnalkhoz" and also give important technical instructions to local metallurgical plants. The organization is comprised of one manager, two assistant managers and about 15 cheifs. Their subjects of study are determined by the National Iron, Steel and Nonferrous Metal Committee. Checking into the iron and steel producing techniques of the whole U.S.S.R., it is not exactly true to say that there is no liberty of selection by an individual researcher. It is said that in some cases the National Iron, Steel and Non-ferrous Metal Committee studies a subject submitted by an individual researcher and takes it up. As to the evaluation of research results there are remarkable differences between the two laboratories. At the Central Iron and Steel Laboratory a committee consisting of each chief investigates subjects very strictly and the results are immediately evaluated as the researcher's grade. On the other hand, the Baikov Memorial Iron and Steel Laboratory is mainly engaged in the fundamental research work setting its goal for the future;

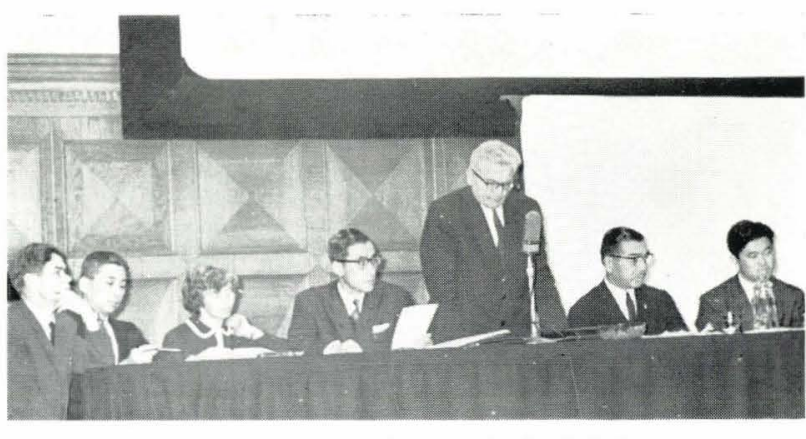

Lecture at the Central Iron and Steel Laboratory

One example of chemical composition

\begin{tabular}{|c|c|c|c|c|c|c|c|c|c|c|c|}
\hline & Grade of steel & $\begin{array}{l}\text { Element } \\
\text { Mark }\end{array}$ & $\mathrm{C}$ & $\mathrm{Si}$ & $\mathrm{Mn}$ & $\mathrm{S}$ & $\mathrm{P}$ & $\mathrm{Cr}$ & $\mathrm{Ni}$ & Mo & $\begin{array}{l}\text { GOST } \\
\text { No. }\end{array}$ \\
\hline \multirow{2}{*}{$\begin{array}{c}\text { Chrome } \\
\text { molybdenum } \\
\text { steel }\end{array}$} & $\begin{array}{l}\text { High quality alloy } \\
\text { steet }\end{array}$ & $30 \mathrm{XM}$ & $0.26-0.34$ & $0.17-0.37$ & $0.40-0.70$ & $\begin{array}{l}\text { Less than } \\
0.035\end{array}$ & $\begin{array}{l}\text { Less than } \\
\quad 0.035\end{array}$ & $0.80-1.10$ & $\begin{array}{l}\text { Less than } \\
\quad 0.25\end{array}$ & $0.15-0.25$ & $4543-61$ \\
\hline & $\begin{array}{l}\text { Extraordinary high } \\
\text { quality alloy steel }\end{array}$ & 30XMA & $0.26-0.33$ & $0.17-0.37$ & $0.40-0.70$ & $\begin{array}{l}\text { Less than } \\
0.025\end{array}$ & $\begin{array}{l}\text { Less than } \\
0.025\end{array}$ & $0.80-1.10$ & $\begin{array}{l}\text { Less than } \\
0.25\end{array}$ & $0.15-0.25$ & 4543-61 \\
\hline
\end{tabular}


therefore, the results are evaluated by the Physical and Chemistry Committee once and, as a rule, they are not strictly evaluated whether successful or not. The Secondary Metal Product Plant Designing Laboratory has no experimental apparatus and thus it is a consultant engineering laboratory, concerning secondary metal products of revet, wire, nut, washer welding rod, etc. This kind of laboratory is peculiar in U.S.S.R. and it belongs to the National Iron, Steel and Nonferrous Metal Committee. All data of secondary product factory in U.S.S.R. are accumulated and arranged in this laboratory. In case a new building or an additional building in a secondary product plant is constructed, such a construction is always designed by this laboratory. After plant building plan is approved by the National Conference of Economy and is passed to the said laboratory, the plant is designed through the use of accumulated data, so as to be constructed most economically and also to increase productivity most effectively. Beside, the location is checked from various angles and the designing plan is submitted. For instance, they would advise whether it should be provided with the open hearth furnace and a rolling mill or should be built together with a general machinery plant. This is, we would say, also the characteristic of a socialistic country, and it is quite easy for them to build newer and more advanced plants than before.

\section{Conclusions}

In U.S.S.R. not only political life but also research organization are centralized. The organizations have huge facilities and most excellently capable personnel in their central organization, a few members of the Iron, Steel and Non-ferrous Metal Committee directing all iron and steel production plants all over the country.

In liberal countries we can not expect any interchange of techniques between companies and for the worse we are keeping expensive laboratories of our own and doing hard research work with few capable men and at great expense in order to compete with others. On the contrary, in socialistic countries there are no secrets among plants at all, and it is really to be envied that all engineers can work on the same difficult technical problems at the same time. As for techniques, self-rehabilitation alone is not good enough. There is no such fool as one who reintroduces an invention that has already been made somewhere else in the world. Minister Boiko also says that it is necessary for a country to exchange mutually with the best of what the country has. As a matter of fact, we could feel it was going this way. What we were most impressed with in U.S.S.R. was the close relationship between laboratories and plants. This characteristic cannot be seen in the free blocs. We ought to learn that products and techniques are developed and advanced by a close relationship between laboratories and plants. 